\title{
Apropriações literárias em Anticristo, de Lars von Trier
}

\author{
Patrícia Kruger*
}

\begin{abstract}
Resumo: Procuramos mostrar aqui como o filme Anticristo (Antichrist, 2009) do cineasta dinamarquês Lars von Trier pode ser analisado atentando-se para suas apropriações literárias. Destacaremos, assim, as relações que o filme estabelece com as elaborações estéticas e algumas obras do dramaturgo sueco August Strindberg e do dramaturgo alemão Bertolt Brecht. Também nos propomos a investigar como o estudo do foco narrativo apresentado pelo filme permitiria uma leitura destoante das que o filme tem recebido e como ferramentas da crítica literária possibilitariam apontar na obra uma armadilha ideológica central para sua interpretação.
\end{abstract}

Palavras-chave: Literatura. Cinema. Lars von Trier. Bertolt Brecht. August Strindberg.

\section{Introdução}

Dentro de uma produção extensa e bastante eclética, é fato que o cineasta dinamarquês Lars von Trier tem constantemente travado relações não apenas com o universo do próprio cinema, mas também com outros segmentos da cultura e das artes, como a filosofia, as artes plásticas, a ópera, a música pop, a dramaturgia e a literatura. Diversas referências têm sido identificadas em suas obras que remontam a estes âmbitos - lembremo-nos, por exemplo, da referência à ópera wagneriana, já presente em Epidemia (Epidemic, 1987) e retomada em seu último trabalho, Melancolia (Melancholia, 2011); ou da importância da música pop em Dançando no escuro (Dancer in the Dark, 2000) e nos intertítulos de Ondas do destino (Breaking the Waves, 1996). Em se tratando de textos literários, e aqui estamos considerando também o texto teatral, Trier tem explicitado a relevância de autores tais como Marquês de Sade, Bertolt Brecht e August Strindberg em vários de seus trabalhos.

Como apontado por Bainbridge (2007), a obra Justine ou os infortúnios da virtude (Justine ou les malheurs de la vertu, 1791) de Sade, que ilustra a virtude jamais recompensada da heroína homônima, é apropriada por Trier no autossacrifício da protagonista de Ondas do destino. Neste filme, a atriz Emily Watson interpreta Bess, uma mulher bastante ingênua e imatura de um vilarejo cuja comunidade é severamente reprimida e controlada pelos ditames da Igreja Presbiteriana. Seu

* Doutoranda pelo Departamento de Letras Modernas - FFLCH - da Universidade de São Paulo (USP). E-mail: kruger.patricia@gmail.com. 
marido, Jan (Stellan Skarsgård), após sofrer um acidente e ficar imóvel, encoraja-a a manter relações sexuais com outros homens e pede, ainda, para que a esposa the narre estas experiências. Ela estaria, assim, também o auxiliando em sua recuperação. $O$ resultado deste sacrifício em nome do amor é que Bess acaba sendo fatalmente estuprada e espancada por um marinheiro em um barco, além de proibida, já que pecadora, de ser enterrada segundo os preceitos da igreja cristã.

Justine está igualmente presente em Melancolia, nomeando uma das protagonistas e servindo de base para a dinâmica de irmãs movidas por ideais conflitantes. Bainbridge (2007) também identifica referência, em Ondas do destino, à peça Senhorita Júlia (1888), de Strindberg, na qual uma jovem aristocrata, ao desafiar convenções sociais de classe e gênero (envolver-se com um criado), é inevitavelmente levada à ruína e ao suicídio. O paralelo com a protagonista do filme é claro, tanto pelo fato de Bess ousar casar-se com um estrangeiro, quanto pela inadequação de sua conduta sexual frente a uma ordem social pautada pela moral cristã ortodoxa.

Bertolt Brecht também se apresenta como referência cara ao cineasta, o que é possível notar, de forma mais marcante, nos filmes Dogville (2003) e Manderlay (2005), expressões contundentes da apropriação de método, forma e conteúdo brechtiano. De fato, embora possamos identificar referências à Brecht desde seus trabalhos mais antigos (Epidemia, de 1987, e Europa, de 1991, por exemplo) é com o lançamento de Dogville que Lars von Trier faz público e notório seu interesse pelo dramaturgo alemão. Como discutido por Evelise Souza em sua tese Dogville, filme e crítica (2007), este interesse não se limitava à temática (segundo Trier, o filme teria inspiração direta na canção Jenny-Pirata, da Ópera dos três vinténs - Die Dreigroschenoper, 1928), nem tampouco se restringia a aspectos formais antiilusionistas, como o cenário riscado a giz, o uso explícito de um narrador, a divisão em capítulos, as personagens sem uma psique bem delineada. Seria na tensão deste modelo "épico" com um substrato próprio do drama, contradição central do filme, segundo a autora, que se localizaria a chave para a compreensão crítica desta obra.

Também em Anticristo (Antichrist, 2009) enxergamos a apropriação crítica tanto de Brecht como de Strindberg. Intentamos mostrar, assim, de que forma tais apropriações são feitas no filme e quais as consequências que emergem de tais escolhas. Ainda no âmbito da literatura, objetivamos também analisar, de uma perspectiva da crítica literária, de que forma a estruturação do foco narrativo apresentado pelo filme constituir-se-ia como cerne para uma abordagem crítica da obra e quais as implicações sociais e políticas que podem ser daí inferidas.

\section{0 método brechtiano em Anticristo}

Por partirmos da observação dos elementos literários presentes em Anticristo, nossa interpretação da obra vai de encontro à forma pela qual o filme tem sido frequentemente recepcionado, na qual é comum encontrarmos a rotulação de filme "misógino" ou a indicação de que o filme endossaria uma visão opressiva das mulheres, visão esta supostamente "defendida" por Lars von Trier. A nosso ver, contudo, graças à apropriação de um método brechtiano (JAMESON, 1999), a opressão 
feminina seria aqui, e também em outros filmes do cineasta, exposta e problematizada por diversos elementos que dificultam uma associação direta entre o conteúdo mostrado e a visão do diretor, ou mesmo uma interpretação naturalista ${ }^{1}$ do filme, como se este trouxesse um retrato fiel da realidade. O gênero de horror e sua representação do feminino, nesse sentido, seriam utilizados como elementos a serem questionados e não como forma total do filme; os materiais que o filme nos apresenta exigiriam, portanto, a compreensão da forma distanciada, brechtiana mesmo, pela qual são expostos e não uma leitura passiva e conivente com os argumentos ideológicos a eles relacionados.

De acordo com esta leitura passiva, o filme traria a história de um casal que, ao fazer sexo, não percebe que o filho lança-se através da janela. A mãe, interpretada por Charlotte Gainsbourg, entra numa crise de luto e seu marido, um terapeuta cognitivista interpretado por Willem Dafoe, propõe uma viagem à cabana que o casal possui no meio da floresta com vista à superação dos ataques de ansiedade da esposa. No entanto, situação acaba saindo do controle. Dafoe ${ }^{2}$ percebe que o tormento de Gainsbourg é de longa data: descobre que a esposa forçava o filho a utilizar os sapatos invertidos. Mais do que isso, que ela não havia terminado sua tese sobre o feminicídio na cultura ocidental, tendo, ao contrário, se identificado com o argumento a ser criticado: o de que há um mal intrínseco às mulheres, justificando sua perseguição. A comprovação da loucura da esposa concretiza-se em seu ataque ao marido. Com receio de que Dafoe a abandone, ela golpeia seus genitais, perfura sua perna e acopla um peso a ela. Logo em seguida, ela mutila seu próprio genital. Dafoe consegue livrarse do peso em sua perna, sofre um novo ataque da esposa e é levado a cometer seu assassinato por asfixia. Ele então queima o corpo da esposa em uma fogueira e deixa a cabana.

Esta difundida compreensão do filme ignora, a nosso ver, dois fatos essenciais para uma abordagem crítica da obra. O primeiro é que, embora as personagens não tenham nome, e grande parte do filme se passe na cabana do casal batizada de "Éden" - o que estimula também a averiguação dos elementos mítico-alegóricos presentes no filme -, somos igualmente informados de que a história se passa nos Estados Unidos, mais precisamente na cidade de Seattle. É justamente neste país que a psicoterapia comportamental cognitiva (cognitive behavioral therapy) tem sua maior difusão, sendo esta baseada em métodos racionalistas que também estruturam, não por acaso, a organização da produção no sistema capitalista, e a própria Constituição Norte-americana, relações estas importantes para a discussão do filme.

1 Utilizamos este termo aqui em consonância com a definição proposta por Xavier: "Quando aponto a presença de critérios naturalistas, refiro-me, em particular, à construção de espaço cujo esforço se dá na direção de uma reprodução fiel das aparências imediatas do mundo físico, e à interpretação dos atores que busca uma reprodução fiel do comportamento humano, através de movimentos e reações 'naturais'. Num sentido mais geral, refiro-me ao princípio que está por trás das construções do sistema descrito: o estabelecimento da ilusão de que a plateia está em contato direto com o mundo representado, sem mediações, como se todos os aparatos de linguagem utilizados constituíssem um dispositivo transparente (o discurso como natureza)". (XAVIER, 1984, p. 42).

2 Uma vez que em Anticristo temos a presença de duas personagens sem nome, iremos nos referir, a título de praticidade, à personagem masculina como Dafoe, e à personagem feminina como Gainsbourg. 
Por ora, vale lembrar que o fato de as personagens não serem nomeadas reforça semelhantemente a leitura distanciada que o filme incita, criando um obstáculo à mera assimilação do enredo do filme e perturbando o mecanismo de identificação tão caro aos filmes hegemônicos. Por conseguinte, embora a estilização brechtiana não se faça aqui tão clara como em Dogville ou em Manderlay, as "técnicas de distanciamento" estão aí presentes: divisão em prólogo, epílogo e capítulos (salientando, inclusive, mais uma intersecção literária na obra); montagem fora do padrão "transparente" do cinema clássico; personagens que subitamente olham em direção à câmera; movimentos oscilantes desta, afirmando a artificialidade da construção cênica; elementos fantásticos, que quebram com a linearidade narrativa e produzem o delineamento explicitamente onírico de diversas cenas; o efeito de estranhamento por meio da música, que comenta o que é mostrado. Todos estes recursos são tributários do caráter anti-ilusionista do filme, impossibilitando, desta forma, uma leitura meramente naturalista da obra.

Ainda no âmbito deste método brechtiano adotado por Trier, notemos aqui a atuação da dinâmica entre o indivíduo e o coletivo, tão cara ao dramaturgo alemão. Assim, as discussões levantadas pelo filme, aparentemente no campo da intersubjetividade, devem também ser estendidas para toda uma coletividade. Não é por acaso a não nomeação das personagens - elas representam grupos, funções sociais: homens e mulheres; e, ao mesmo tempo são historicamente situadas: um núcleo familiar norte-americano, formado por dois intelectuais, situados na contemporaneidade. Desta forma, as questões concernentes à opressão feminina devem ser contempladas de uma forma dialética que dê conta de sua inter-relação entre o plano histórico e social e o plano do indivíduo e de sua subjetividade, inclusive de sua construção psíquica, como iremos expor mais adiante.

Ampliando um pouco mais nossa observação das apropriações brechtianas em Anticristo, chegamos ao segundo fato essencial para a interpretação do filme, fato este também amplamente ignorado pela crítica: a estruturação de uma armadilha ideológica, qual seja, uma elaboração artística cara a Brecht que permite que uma cilada, uma mistificação, um engodo seja desfeito. Neste caso, a armadilha dá-se com a estruturação do filme através de um foco narrativo determinado, que acreditamos estar vinculado à personagem de Willem Dafoe. Apresentando uma determinada visão de mundo, tal foco insere-se numa estrutura maior, o ponto de vista do filme, que comenta, desmente, perturba e coloca à prova nosso narrador. Esta armadilha, quando não percebida, ou seja, quando ignorado que o filme possui um narrador cuja versão dos fatos deve ser encarada com cuidado, pode levar às inúmeras interpretações falaciosas da obra, que enxergam nela, por exemplo, uma afirmação da misoginia.

Devemos, assim, atentar ao risco da aderência à narrativa da personagem masculina, aderência que é alimentada por ser ele um terapeuta, um homem da Ciência, da Razão, disposto a ajudar sua esposa a superar o trauma da perda do filho. A tarefa que nos cabe é perceber que, assim como ele conduz a esposa por meio de sua abordagem racional de tratamento da dor, ele também está conduzindo a audiência a compartilhar de sua ótica, como se esta fosse a ótica do filme. Contudo, os 
indícios de que a condução da narrativa é feita tão somente por Dafoe estão espalhadas por todo o filme, sublinhando seu papel central na configuração da história. Para tanto, basta notar que a câmera subjetiva relaciona-se comumente com o seu olhar, e que pouquíssimas cenas se dão na presença isolada da personagem feminina, ao contrário dos vários momentos centrados na personagem masculina, que também é a única a presenciar acontecimentos "fantásticos", como a famosa cena em que uma raposa, em meio a seu autodilaceramento, exclama: "o caos reina".

O filme demandaria, assim, o reconhecimento da necessidade de uma leitura a contrapelo, uma inversão do sinal que acompanha os argumentos ideológicos aí apresentados. A percepção desta exigência dá-se justamente quando nos atentamos de que Anticristo, por apresentar uma elaboração político-estética próxima da de Bertolt Brecht, estimula, por meio do uso da armadilha, o estranhamento dos argumentos aí presentes, argumentos estes que frequentemente coincidem com as concepções de mundo hegemônicas. A adesão ao campo da moral, dos dualismos simplistas e mesmo do pensamento lógico (em oposição ao pensamento dialético), caminho do assentimento do foco narrativo associado à personagem masculina, impede, portanto, uma leitura que enxergue o ponto de vista do filme. Este apontaria, assim, na contramão dos argumentos apresentados por Dafoe, não as explicações da ordem da natureza e da imutabilidade, mas sim as relações estruturais que determinam certos tipos de comportamento, como a conjunção de cristianismo, patriarcalismo e capitalismo para a manutenção de violências físicas e psicológicas contra a mulher.

$\mathrm{Na}$ peça de Bertolt Brecht $A$ exceção e a regra (Die Ausnahme und die Regel, publicada em 1937) temos um movimento semelhante. A peça apresenta a viagem de um comerciante de petróleo e dois trabalhadores - um guia sindicalizado e um carregador (cule) - através do deserto. Seu objetivo é chegar antes dos concorrentes a um novo poço de petróleo. No percurso da viagem, o guia acaba demitido e o cule é assassinado pelo comerciante, que, no final da peça, é absolvido pelo juiz e isentado do pagamento de indenização à viúva do cule. Vale notar que a peça, embora estruturada a partir da perspectiva do comerciante, não toma, no entanto, seu partido. Uma montagem que ignorasse este distanciamento poderia, inclusive, cair facilmente num dualismo esquemático (vilão $X$ mocinho), sem perceber que o sentido da obra se configura nas tensões e contradições entre as personagens, e em relações estruturais, como as que mencionamos há pouco.

É justamente na construção destas relações que se dá o ponto de vista do filme, responsável por mostrar a voz dos descompassos, por exprimir as contradições da obra - correspondendo, entre outros processos, ao conflito entre seus diferentes registros. Localiza-se aí também, a nosso ver, o autor implícito, instância transferida do universo literário que problematiza as acepções associadas ao foco narrativo, comenta o universo de relações sob análise, constrói as vinculações entre as cenas e organiza a noção de totalidade presente no filme. É esta instância, inclusive, a que responde pelos processos extradiegético, forçando o espectador a travar relações entre domínios aparentemente desconexos - como os conteúdos transmitidos verbalmente e os transmitidos pelas imagens. Mauro Pommer (2003, p. 07), apesar de referir-se a esta instância apenas como "Autor", explicita que a relevância de se analisar seu ponto de vista 
[...] está em colocar em evidência, a propósito de um determinado filme, aquilo que figura apenas indiretamente na narrativa, isto é, as informações que são passadas ao espectador pelas estratégias próprias ao trabalho de direção cinematográfica. Nesse caso, podemos buscar explicitar o que nos comunicam a música, a intensidade e a composição dos ruídos, a iluminação, a composição dos enquadramentos, a decupagem, o movimento de câmera.

O autor implícito seria, assim, responsável por incitar brechtianamente o espectador a enxergar as questões colocadas no seio de uma aparente evidência e por oferecer diversas pistas que problematizam a versão dos fatos exposta por Dafoe. Como um dos exemplos de sua interferência, podemos destacar a letra da ária Lascia ch'io pianga, da ópera Rinaldo de Händel. A ópera baseia-se no poema épico La Gerusalemme Liberata, e trata da Primeira Cruzada Cristã. A tradução de sua letra seria a seguinte:

Deixe que eu chore/ minha sorte cruel, / e que suspire/ pela liberdade!/

Que a dor quebre/ estas cadeias/ de meus martírios, / só por piedade! ${ }^{3}$

A princípio, se atentarmos à letra, já poderemos notar certo descompasso entre o que é mostrado e o que é dito. Por que, em uma cena em que a personagem feminina vivencia um grande êxtase sexual, esta voz, também feminina, falaria em dor, e em "suspirar pela liberdade"? Destaca-se, assim, um embate entre o conteúdo que é cantado e o que é mostrado, uma espécie de confronto tese-antítese que tem por objetivo induzir o espectador a extrair uma síntese final, movimento este que, aproximando-se claramente dos preceitos do teatro dialético de Brecht, nega-se a "envolver o espectador numa ação cênica" (ROSENFELD, 2006), o que é amplamente feito no cinema hegemônico, onde em que a trilha sonora apenas corrobora o que é mostrado, de forma redundante.

Neste caso em questão, o objetivo é tornar o espectador um observador, despertando sua atividade e forçando-o a tomar decisões. A contribuição do autor implícito funcionaria, assim, como uma referência extrafílmica à imagem exibida, transportando o espectador às dores da jovem Almirena, que lamenta seu triste destino longe de seu amado Rinaldo após ser sequestrada pela feiticeira e rainha de Damasco, Armida. Vale destacar que muitos temas da ópera Rinaldo podem ser levantados e confrontados com as temáticas do filme: a ação da ópera se passa em Jerusalém, durante a Primeira Cruzada, o que implica a validade de uma aproximação entre a retórica imperialista cristã - aí inclusos seus diversos registros misóginos - e as reminiscências deste discurso numa ordem contemporânea que ainda é bastante sexista.

Ainda a respeito do espectador-observador, um dos aspectos que gostaríamos de salientar na apropriação trieriana do já mencionado método brechtiano relaciona-se justamente à recepção da obra, ao trânsito entre obra e espectador. É neste movimento que vemos a aposta de Lars von Trier na reflexão crítica da audiência de seu filme: as questões sem respostas, as obscuridades, as incompletudes, os

\footnotetext{
${ }^{3}$ Nossa tradução.
} 
processos inquietantes são aspectos materiais e concretos de sua obra, que exige a produção de seu sentido último no movimento de intervenção na realidade. Apenas como caráter ilustrativo, pensemos na incineração de Gainsbourg no final do filme, ou nas imagens oriundas de manuais da Inquisição, no sótão da cabana, e no estímulo que estas imagens trazem para se investigar significados submersos na constituição do filme, significados estes que precisarão necessariamente ser relacionados a materiais da esfera da história e da política.

Voltando a nossa compreensão do foco narrativo do filme como sendo vinculado à personagem masculina, faz-se necessário um importante acréscimo, que nos levaria a mais uma apropriação literária importante de Anticristo. Este foco narrativo funcionaria, a nosso ver, de maneira semelhante ao discurso não confiável de um narrador em primeira pessoa, com uma estruturação, contudo, mais complexa: aqui haveria a materialização da esfera psíquica da personagem de Dafoe, como se o filme ilustrasse os processos mentais velados, mas historicamente condicionados, de uma determinada subjetividade, e sua relação a determinado(s) discurso(s) hegemônico(s) - como o patriarcalismo e as ideologias que estabelecem o que é o "feminino", e de que forma esta "entidade" pode ser bastante "ameaçadora".

\section{Strindberg em Anticristo}

Nesse sentido, a constelação de imagens e acontecimentos irreais (como a raposa falante), as indeterminações de causalidade, as inúmeras referências diegéticas e extradiegéticas ao universo dos sonhos configuram, de fato, antes uma exposição de acontecimentos psíquicos ocultos, vinculados a um ego determinado, em relação ao qual e a partir do qual todas essas manifestações ocorrem, do que uma realidade propriamente dramática. Esta configuração dá-se de maneira semelhante ao que ocorre em inúmeras peças do dramaturgo sueco August Strindberg, como em O Pai (1887) ou em Rumo a Damasco (1898-1901). Também nessas peças, ao invés de relações intersubjetivas, próprias ao drama, o que se apresentam são desdobramentos da psique do protagonista, cabendo a elas, portanto, a classificação de "dramaturgia do eu" (SZONDI, 2001), que também enxergamos em Anticristo.

No caso específico de Strindberg, podemos observar como a esfera da intersubjetividade, em crise no final do século XIX, necessita a partir de então de uma representação que se baseie muito mais na projeção de uma monossubjetividade. Neste sentido, vale observarmos, na companhia de Szondi, a peça $O$ pai. Aparentemente um drama familiar, representação direta da disputa entre pai e mãe pela determinação do destino da filha, a peça consolida-se, contudo, em uma análise mais profunda, no embate atemporal entre homens e mulheres projetado singularmente da perspectiva de sua "personagem-título e se desenrola mediada por sua subjetividade" (SZONDI, 2001, p. 55). A aproximação que objetivamos construir com Anticristo tem aqui sua primeira demonstração, uma vez que, no filme, também enxergamos o desenvolvimento da história a partir da subjetividade da personagem masculina. No ataque extremo exposto no filme, de Gainsbourg contra Dafoe, instaura-se movimento semelhante ao que Szondi descreve em relação à peça: "Mais 
importante é reconhecer que a luta de sua mulher contra ele só alcança de modo geral a realização "dramática" como reflexo em sua consciência, que os traços principais do protagonista são definidos por ele mesmo" (SZONDI, 2001, p. 55).

Em Anticristo, similarmente, o ataque de Gainsbourg é também reflexo da consciência do protagonista, Dafoe, como se a narrativa que observamos no filme fosse não o "mundo objetivo, autônomo e absoluto, em que cada personagem fala, vive e atua de próprio direito e impulso - convenção básica da Dramática rigorosa" (ROSENFELD, 2006, p. 99), mas sim uma construção de caráter expressionista, explicitando o que se passa no interior de uma subjetividade determinada. Assim, o argumento principal que justifica a insanidade de Gainsbourg, sua identificação com a tese que deveria criticar, é também uma transferência à personagem de Gainsbourg de acepções próprias da subjetividade cuja exteriorização se dá no filme: Dafoe. Da mesma forma que o Capitão de $O$ pai, ele suspeita de pensamentos que podem ocorrer na cabeça de Gainsbourg e os projeta na tela como as ações e palavras da esposa, o que devemos encarar como afastado de uma representação direta, dramática da realidade por meio da análise das diversas pistas espalhadas pelo autor implícito.

É interessante notar como a utilização de uma técnica dramática consolidada por Strindberg serviria para revelar a narrativa de Anticristo antes como as contradições e pensamentos inomináveis de uma subjetividade, do que um embate de ideias próprio do drama convencional. Vale também indagar qual seria a relevância da atualização desta estrutura. Neste caminho, poderíamos esbarrar na validade de uma elaboração artística que, apesar de aparentemente anacrônica, serve à exposição da permanência, na contemporaneidade, de conformações psíquicas sustentadas por um modelo de conduta social ainda bastante íntimo da estrutura patriarcal do século XIX.

Avançando um pouco mais nas relações de Anticristo com obras de Strindberg que fazem uso de tal estrutura formal, faz-se necessária a aproximação do filme de Trier à peça Rumo a Damasco, uma trilogia de peças publicada pelo dramaturgo sueco em 1898 (primeira e segunda partes) e entre 1900 e 1901 (terceira parte). Nela, acompanhamos o percurso e a luta interior da personagem principal, o "Desconhecido" para alcançar, ainda que de forma hesitante, sua conversão espiritual. No caminho, passa por diversas "estações", abdicando, em cada uma delas, de elementos, coisas terrenas, renome científico e mulheres. Nas palavras de Rosenfeld (2006, p. 100), a peça se configuraria como uma "imensa trilogia que é uma verdadeira 'paixão' do Desconhecido, personagem central que atravessa os momentos principais de sua vida, cercado de personagens simbólicos".

Referindo-se à Rumo a Damasco, Szondi (2001, p. 60) afirma:

No "drama de estação", o herói, cuja evolução se descreve, é distinguido com máxima clareza das personagens que encontra nas estações de seu caminho. Elas só aparecem na medida em que encontram com o protagonista, na perspectiva dele e em relação a ele. $E$, uma vez que a base do "drama de estação" não é constituída por um grande número de personagens colocados até certo ponto no mesmo nível, mas sim por um eu central, seu espaço não é, portanto, dialógico a priori, e inclusive o monólogo perde aqui o caráter excepcional que necessariamente possui no drama. Mas só assim a abertura ilimitada de uma "vida psíquica oculta" recebe uma fundamentação formal. 
No filme, o que se estrutura é também a investigação de uma esfera psíquica mais profunda, em consonância com os desenvolvimentos freudianos acerca do inconsciente e da configuração onírica. Anticristo, assim, de forma análoga, não se ocupa com uma representação que, de acordo com os preceitos da dramaturgia clássica, apresenta personagens que se conhecem intimamente e cujo embate é, portanto, com o mundo exterior, mas sim com a exposição expressionista dos conflitos e contradições, historicamente moldados, que compõem a matéria do inconsciente, dos sonhos, dos pesadelos e da loucura. Como proposto por Rosenfeld (2006, p. 101), a respeito de Rumo a Damasco,

Se no drama naturalista o "individuo clássico" se vê pressionado pelas forças externas do mundo-ambiente, no drama subjetivo, expressionista, a pressão vem de dentro, dos próprios abismos subconscientes que se afiguram anônimos e impessoais da mesma forma que aquelas. É legitimo conceber os personagens de $O$ Caminho de Damasco como projeções inconscientes do personagem central, a "Senhora", p. ex., como materialização de um anseio ou desejo onírico. ${ }^{4}$

Dafoe, similarmente, não apenas materializa anseios, desejos e concepções na figura de Gainsbourg ou na solidificação de visões e personagens simbólicos (como os animais), mas a conformação destes aos processos psíquicos do ego central da história é mostrada objetivamente por meio de processos de identificação explícitos. No caso de Gainsbourg, a indiferenciação entre subjetividades distintas (ele e ela) dá-se de diversas formas: as imagens em branco e preto, com foco deslocado, mostrando partes do corpo de Gainsbourg sofrendo de ansiedade, misturam-se com fragmentos do corpo do próprio Dafoe, momentos antes do assassinato da esposa. Além disso, na pirâmide terapêutica que ele elabora, a culminação na principal fonte de pavor dela como "eu" - "me", no original - abre espaço para esta identificação bastante ambígua: "me" é atribuído tanto a Gainsbourg quanto a Dafoe.

Aqui, de forma semelhante à peça, temos as "revelações do inconsciente de um sonhador" (ROSENFELD, 1985, p. 101) ou, talvez, dos processos análogos aos dos sonhos perceptíveis na constituição psíquica de um determinado sujeito (um intelectual norte-americano branco e do sexo masculino) e que solidificariam uma velada, mas hegemônica, concepção de mundo. As palavras de Strindberg para descrever sua peça posterior à Rumo a Damasco, não por acaso chamada Um Sonho (1902), encaixam-se muito bem à leitura que almejamos desenvolver de Anticristo, se mais uma vez atentarmos à proximidade entre "um sonhador" e "constituição psíquica de um determinado sujeito":

Como fizera em sua peça onírica anterior, também aqui o autor tentou imitar a forma desconexa, mas aparentemente lógica do sonho. Tudo pode acontecer; qualquer coisa é possível e provável. Tempo e espaço não existem. Sobre um fundo insignificante de realidade, a imaginação projeta e borda novos padrões: uma miscelânea de memórias, experiências, fantasias livres, absurdos e improvisações. As personagens dividem-se, duplicam-se, multiplicam-se, desvanecem, solidificam-se, tornam-se obscuras e claras. Mas uma consciência reina sobre tudo isso - a do sonhador; e diante dela não há segredos, não há incongruências, não há escrúpulos e não há leis. (STRINDBERG, 1902, p.24).

${ }^{4}$ Anatol refere-se à peça como $O$ Caminho de Damasco, embora sua tradução mais comum para o português seja mesmo Rumo a Damasco. 
Ainda sobre a presença de Strindberg em Anticristo, não há como não mencionarmos sua obra Inferno, originalmente publicada em 1897, como fonte literária de clara inspiração para Anticristo. A obra, de caráter autobiográfico, foi escrita como um diário repleto de crises psicóticas, surtos, visões e tormentos pelos quais o autor sueco teria passado quando de sua residência longe de sua terra natal, principalmente em Paris. O próprio Lars von Trier cita, no material de divulgação do filme (2009, p. 5), a intersecção deste com a obra Inferno, admitindo que o filme seria fruto de sua própria crise de depressão durante os anos de 2007 e 2008:

Eu li Strindberg quando eu era jovem, eu li com entusiasmo as coisas que ele escreveu antes de ir para Paris para se tornar um alquimista e durante sua estadia lá...o período depois chamado sua "inferno crisis" - seria Anticristo minha Inferno Crisis? Minha afinidade com Strindberg ${ }^{5}$

Seu interesse por Strindberg pode também ser atestado em outro relato, mais antigo, no livro de entrevista Trier on von Trier (BJÖRKMAN, 2003, p. 28). Quando questionado acerca de suas inspirações no âmbito das artes plásticas e da literatura, Trier diz ter lido muito quando jovem, especialmente Strindberg. Para ele, a loucura de Strindberg e de Edvard Munch foi o ápice do romantismo artístico, sendo que, após o tratamento psiquiátrico com o médico dinamarquês Professor Jacobson (ambos submeteram-se a seus cuidados), os romances de Strindberg teriam ficado muito mais enfadonhos. Segundo o cineasta, embora os artistas possam ter se sentido melhor, sua arte havia sido comprometida por meio dos tratamentos; o psiquiatra seria, a seus olhos, uma espécie de vilão, e os artistas, em geral, estariam destinados a passar por maus momentos, pois isso tornaria seus resultados muito melhores.

Baseando-se neste relato e em seu próprio tratamento com terapia cognitiva pouco antes da produção de Anticristo, poderíamos cogitar uma transferência para o filme de sua concepção acerca do trabalho do terapeuta, além da figuração, neste, de aspectos relativos à sua própria comparação pessoal com Strindberg. Neste caso, contudo, o "inferno" de Trier, materializado em Anticristo, ilustraria, para nós, uma projeção psíquica permeada de simbolismo e construções imagéticas notadamente românticas, que, ainda que semelhante a aspectos de Inferno, faz parte da perspectiva subjetiva da personagem masculina.

\section{Escolhas significativas}

Como procuramos mostrar, as escolhas literárias que estruturam a obra Anticristo não são neutras, cada uma carregando em si uma carga importante de significado: seja por meio da eleição de um foco narrativo que escancara violências já naturalizadas, como as oriundas do patriarcalismo; seja por meio das diversas referências à obra e ao método artístico de Bertolt Brecht, reforçando a importância do espectador como signo ativo da obra, a determinante relação do filme com a história e sua indissociável carga política; ou, ainda, pelo uso de uma técnica expressionista (cunhada por Strindberg) que salienta a importância dos processos psíquicos na constituição do indivíduo e a relação destes com os discursos hegemônicos que os moldam.

\footnotetext{
${ }^{5}$ Nossa tradução.
} 
Tais apropriações, para além do enriquecimento estético que conferem a obra, contribuem, ainda, de maneira expressiva para seu entendimento em uma chave bastante diversa: indo de encontro ao cinema hegemônico, com sua forma clara e familiar, Anticristo oferece-nos, mais do que respostas: oferece-nos inquietações e questionamentos, elementos estes que também estão presentes em Brecht e em Strindberg, e que ajudam a plasmar obras de arte que não mimetizam as aparências do mundo, mas estimulam e enaltecem a compreensão de suas dinâmicas mais profundas.

\section{Referências}

BAINBRIDGE, Caroline. The cinema of Lars von Trier: authenticity and artifice. Londres: Wallflower Press, 2007.

BJÖRKMAN, Stig. (ed) Trier on von Trier. London: Faber and Faber, 2003

BRECHT, Bertolt. A exceção e a regra. Trad. de Geir Campos. In: Teatro completo. V. 4. 2a. ed. Rio de Janeiro: Paz e Terra, , 1994.

JAMESON, Fredric. O método Brecht. Trad. de Maria S. Betti; Rev. Técn. Iná Camargo Costa. Petrópolis: Vozes, 1999.

POMMER, Mauro Eduardo. A defasagem entre história e narrativa no discurso cinematográfico. Seções do imaginário, Porto Alegre, v. 9, p. 5-10, 2003.

ROSENFELD, Anatol. O teatro épico. 4a ed. São Paulo: Perspectiva, 2006.

SADE, Marquês de. Justine ou os infortúnios da virtude. Rio de Janeiro: Saga, 1968.

STRINDBERG, August. The road to Damascus (1898-1901). Book from Project Gutenberg. Disponível em: http://www.gutenberg.org/ebooks/8875. Acesso em 12 agosto 2013.

O pai. In: Senhorita Júlia e outras peças. Trad. de Gulherme da

Silva Braga. São Paulo: Hedra, 2010.

. Inferno. Trad. de Ivo Barroso. São Paulo: Hedra, 2010.

The dream play. In:

Plays by August Strindberg. Trad. e introd. de

Edwin Björkman. London: Duckworth \& Co., 1902. Disponível em:

http://archive.org/details/playsbyaugustst00bjgoog. Acesso em 24 abril 2013.

SOUSA, Evelise Guioto. Dogville, filme e crítica. 2007. Dissertação (Mestrado)Faculdade de Filosofia, Letras e Ciências Humanas, Universidade de São Paulo, São Paulo, 2007

SZONDI, Peter. Teoria do drama moderno (1880-1950). Trad. de Luís Sérgio Repa. São Paulo: Cosac \& Naify Edições, 2001.

TRIER, Lars von et al. Antichrist. Array: Criterion Collection, 2010. (108 min).

. Director's Confession. In: . Pressbook of the film Antichrist.

London: Artificial Eye Film Company, 2009.

XAVIER, Ismail. O discurso cinematográfico: a opacidade e a transparência. São Paulo: Paz e Terra, 1984. 
Title: Literary Appropriations in Antichrist, by Lars von Trier

Abstract: Our aim is to show in which way the film Antichrist (2009), by Lars von Trier, might be analyzed by focusing in its literary appropriations. We shall enhance, thus, the relations the film establishes with the aesthetic elaborations and some works by August Strindberg and Bertolt Brecht. We also intend to inquire how the study of the point-of-view presented by the film would enable a reading dissonant from the ones the film has received, and how literary criticism tools would make it possible to point, in the work, an ideological trap central to its interpretation.

Keywords: Literature. Cinema. Lars von Trier. Bertolt Brecht. August Strindberg.

Recebido em: 15/09/2013. Aceito em 30/11/2013 